\title{
Right Whale Balaena glacialis Sightings Near Hawaii: A Clue to the Wintering Grounds?
}

\author{
L. M. Herman, C. S. Baker, P. H. Forestell and R. C. Antinoja \\ Departments of Psychology and Zoology, University of Hawaii at Manoa, 2430 Campus Road, Honolulu, Hawaii 96822, USA
}

\begin{abstract}
Two sightings of the extremely rare North Pacific right whale Balaena glacialis were made during regular surface and aerial observations of the winter assembly of humpback whales Megaptera novaeangliae in Hawaiian waters. On March 25, 1979 a right whale was observed schooling with 8-9 humpback whales. On April 10, 1979 at a location approximately 122 km from the first sighting, a right whale was seen schooling with a single humpback whale. Markings, together with ancillary observations of others, suggest that the two sightings were of the same animal. At the first sighting, the right whale schooled closely with the humpbacks, surfacing and submerging synchronously with the other whales. At the second sighting, the humpback whale directed what appeared to be courtship behavior toward the right whale, including ventral display, rubbing the right whale with its long pectoral fin, and nudging the flanks and genital area with the head. The right whale ventrally presented on one occasion, but otherwise remained passive a few meters below the surface. The location of the wintering grounds of the North Pacific right whale have long been a mystery. Speculations from whalers' records that Hawaii may have been a wintering ground are strengthened by these current sightings. The possibility that the numerically superior humpback whales may have 'acoustically' displaced the right whales in the Hawaiian breeding areas is discussed.
\end{abstract}

\section{INTRODUCTION}

All of the 10 recognized species of baleen whale appear to engage in annual migrations between higher-latitude summer feeding grounds and lowerlatitude wintering grounds, though the range of the migration may vary greatly among species (Davies, 1963; Tomilin, 1967; Yablokov et al., 1972). The migration to lower latitudes seems motivated by a complex of factors, including the generally lowered productivity of high-latitude waters during the winter (Marr, 1962) and possibly, for some species, the thermoregulatory advantage of rearing calves in warmer waters. The bowhead whale Balaena mysticetus appears to be unique among the baleen whales in having solved the problems of over-wintering in subpolar waters (Davies, 1963).

Only the humpback whale Megaptera novaeangliae (Dawbin, 1966; Herman and Antinoja, 1977), the gray whale Eschrichtius robustus (Scammon, 1874; Rice and Wolman, 1971), and the North Atlantic and Southern Hemisphere stocks of right whales Balaena glacialis (Scammon, 1874; Townsend, 1935; Tomilin, 1967; Gilmore, 1969) are known to form regular winter coastal concentrations in shallow bays or lagoons, or on outlying shallow banks. The remaining whale species more often assemble in small, dispersed groups in deeper oceanic water (Tomilin, 1967). There is no reason to expect that the North Pacific stock of right whales would be different in its winter migration pattern from stocks in the North Atlantic and Southern Hemisphere. Yet, historically, extensive searches in eastern North Pacific regions for winter concentrations of right whales have failed to uncover the expected near-shore assembly areas (Rice, 1974). In the mid-nineteenth century, when right whales were considerably more abundant than today, and were being actively sought by whalers (Gilmore, 1956), the whaling captain Charles Scammon (Scammon, 1874) remarked, 'It has ever been a matter of mysterious conjecture with the most philosophical whalemen, where the northern Right Whales go to bring forth their young, and whither they migrate during the winter months (p. 67)'. Scammon, who discovered the gray whale calving grounds in the bays along Baja California, was unable to locate any right-whale wintering grounds along the west coast of North or Central America.

Any North-Pacific wintering grounds would be especially difficult to uncover today, because of the severe depletion of the right-whale stock. No species of whale in the North Pacific has been brought closer to the edge of biological extinction. Estimates of current 
abundance range from as low as 'a few' to 80 individuals (Rice, 1974; Wada, 1978) to a maximum of between 100-200 individuals (Wada, 1973). Dale Rice (personal communication) has noted that Wada's 1973 and 1978 numbers were derived from different estimation techniques. Rice and Fiscus (1968) state that in the 30year period between 1937-1967, right whales were reported only 10 times in the eastern North-Pacific south of $50^{\circ} \mathrm{N}$. Lat. Annual sightings of right whales by Japanese pelagic whalers operating in the central and western North Pacific summer feeding grounds between 1954-62 ranged from 10-106 individuals (Omura et al., 1968). These data underscore the rarity of the North Pacific right whale. Gilmore (1978) - who found a Southern Hemisphere right-whale winter concentration in the shallow lagoons along Argentina's Patagonian coast in the South Atlantic Ocean (Gilmore, 1969; see also Payne, 1976) — has discussed the enigma surrounding the location of the North Pacific right-whale wintering grounds. He pondered whether Hawaii may have been a wintering ground, but was unable to find sufficient data to support the hypothesis. We now report two sightings of a right whale within Hawaiian waters. The right whale was schooling with one or several humpback whales. A population of several hundred humpback whales assembles each winter in the waters surrounding the main Hawaiian Islands (Herman and Antinoja, 1977). The severely depleted status of the right-whale stock, the long-term mystery about the location of a winter concentration in the North Pacific, and its schooling with another species of baleen whale generate special interest in the sightings and their implications.

\section{SIGHTING LOCATIONS AND IDENTIFICATION OF SPECIES}

The two sightings - one on March 25th, 1979, the second on April 10th, 1979 - were made by members of the University of Hawaii research team studying the annual winter assembly of humpback whales in Hawaii.

The whale sighted on March 25th, by team member Antinoja, was in waters of 145 to $160 \mathrm{~m}$ depth between the islands of Maui and Kahoolawe, at approximately $20^{\circ} 40^{\prime} \mathrm{N}$. Lat, $156^{\circ} 35^{\prime} \mathrm{W}$. Long. It was schooling with a pod of 8 to 9 humpback whales, accompanied by 4 to 6 bottlenosed dolphins Tursiops gilli. Observations of the right whale were made for some $30 \mathrm{~min}$ from a $3-\mathrm{m}$ inflatable rubber craft at distances as close as $30 \mathrm{~m}$. Figure $1(\mathrm{a}-\mathrm{c})$ shows head, back and flukes of this animal, and confirms its identification as a right whale. Between March 25 and 31, the team continued daily boat observations between the islands of Maui, Kahoolawe and Lanai, but did not see the right whale again.

The April 10th sighting, by team members Forestell and Baker, was made during a regularly-scheduled aerial survey of the humpback-whale population. The right whale in this case was with a single humpback whale in waters of $55 \mathrm{~m}$ depth in the Penguin-Bank

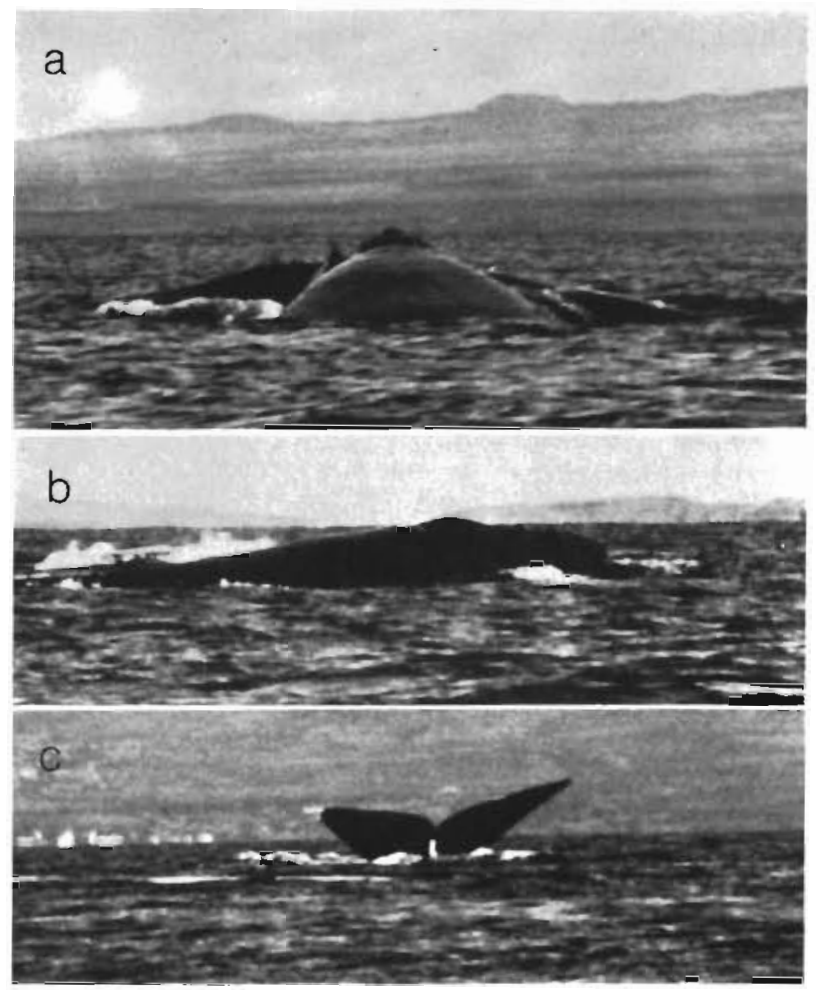

Fig. 1. Balaena glacialis. (a) head, (b) back, (c) flukes of individual sighted on March 25th at ca $20^{\circ} 40^{\prime} \mathrm{N}$. Latitude, $156^{\circ} 35^{\prime} \mathrm{W}$. Longitude

region, which extends south-westerly from the island of Molokai. Its position was $21^{\circ} 03^{\prime} \mathrm{N}$. Lat, $157^{\circ} 30^{\prime} \mathrm{W}$. Long., approximately $122 \mathrm{~km}$ swimming distance west-northwest of the March 25th sighting. Figure 2 $(\mathrm{a}-\mathrm{c})$ shows various aspects of this animal. The white mark on the back appears in other photographs taken at the time. Though this marking was not observed by us at our March 25th sighting, the view of the whale was limited at that time. We later learned that a March 25th sighting by others of a right whale, approximately $28 \mathrm{~km}$ from our sighting and perhaps some 4 h earlier, did reveal the white blaze on the back. From this we can conclude that at least one right whale was present in Hawailan waters for a $16-d$ period, and that the two sightings on March 25th were probably of the same individual. 

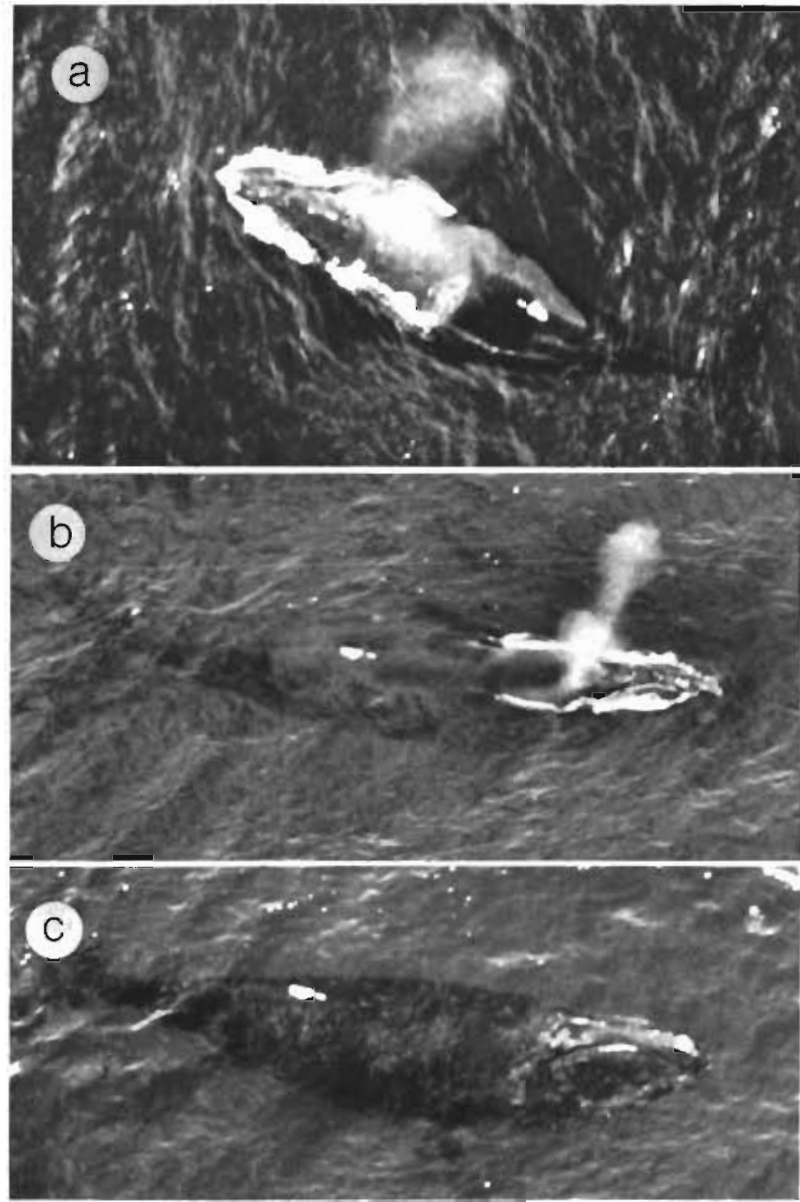

Fig. 2. Balaena glacialis. Various aspects of an individual sighted on April 10 at $21^{\circ} 03^{\prime} \mathrm{N}$. Latitude, $157^{\circ} 30^{\prime} \mathrm{W}$. Longitude

\section{BEHAVIORAL OBSERVATIONS}

For the approximate 30-min period of observation of the first right whale seen, it either remained with the entire group of humpback whales or with one of three subgroups that were later formed from the main group. While intact, the main group tended to spend the majority of its time milling near the surface. Pectoral fins of the humpback whales were thrust in the air, and flukes were displayed frequently above the surface. When the main group finally fragmented into subgroups, each going in separate directions, the right whale was judged to remain with a subgroup consisting of one or two humpbacks. The largest subgroup was followed, but it was several minutes before it was apparent that the right whale was not present. We turned back, but were unable to re-locate the right whale.

While it remained with the main group, the right whale tended to surface together with some of the humpbacks, and to submerge with them, throwing its tail flukes. The flukes almost invariably were rolled to one side on entering the water, as if the right whale was turning or rotating its body as it submerged (Fig. 1c). We have occasionally seen similar rolling behavior in humpbacks, but its frequency and consistency here were unusual. The right whale was also observed swimming on one side near the surface, with one half of the tail fluke exposed. The taped field notes describe the huge size of the flukes, and report, 'The tail fluke comes around (sideways) in one direction and then the other... the tail is swerving in the water ... but it doesn't give the thrashing appearance that frequently occurs when that behavior normally appears (in humpback whales)'. On those occasions when we have seen humpbacks engage in similar sideways 'tail swishing' behavior, a spray of white water was invariably thrown up

The right whale-humpback whale pair sighted on April 10 th was at a distance of approximately $500 \mathrm{~m}$ from another pod of two humpback whales, but did not appear to draw any closer during the 14-min observation period. On the basis of photographs, the right whale was judged to be approximately $20 \%$ longer than the humpback, and was much broader. The observers noted that the humpback may have been a subadult. During most of the observation period, the right whale remained nearly stationary approximately 8-10 $m$ below the surface. It did surface on two occasions, but very slowly, without tail movements, as if rising only by buoyancy adjustments.

When the pair was first sighted, the humpback whale was at the surface, some 30-m distance from the submerged right whale. The humpback then approached the right whale on the surface, swimming directly over it and rolling to one side while waving its pectoral fin. The humpback whale then moved 30-40 m away, coincident with the right whale surfacing for the first time. As the right whale re-submerged, the humpback swam over to it again, this time approaching the right whale's genital area from below. The humpback then swam up and over the back of the right whale, stopped, turned on its side, and rested its ventral surface against the right side of the right whale. The long, left pectoral fin of the humpback whale was extended and partially wrapped around the back of the right whale, as though caressing it. In apparent response, the right whale rolled sideways and presented its ventral surface to the humpback.

The sequence was interrupted when the humpback again swam away a short distance. However, it shortly returned once again toward the genital region of the right whale, drew close, rolled on its side, and gently contacted the flanks of the right whale with its head. As before, it lay its pectoral fin over the back of the 
right whale. When the right whale surfaced for the second time, the humpback remained immediately below it. The head of the humpback was clearly posterior to the head of the right whale, while its flukes protruded just beyond those of the right whale. The back of the humpback whale appeared to be touching the ventral surface of the right whale.

The taped descriptions report, 'the humpback whale rolled over on the right whale's back and pec slapped (slapped its pectoral fin) on the right whale's back.' Also, 'the humpback came in and caressed the underside of the right whale with its pec fin.' The pectoral fins of the humpback whale are commonly used in intra-specific encounters that may involve courtship (Herman and Forestell, 1977). Also, the head is often used to rub another individual especially along the flanks, near the genitals, and around the head. The type and sequence of interactions reported here between humpback whale and right whale give the strong impression that the humpback whale was engaging in courtship behavior. Aside from the single ventral presentation described, the right whale appeared passive throughout the observation period.

\section{DISCUSSION}

Gilmore's (1978) speculation that the Hawaiian Islands might have been a winter assembly area for the right whale was based in part on the Townsend and Watson charts (Townsend, 1935) summarizing locations of 19th-century whale kills. These show several right whales taken at approximately $1900 \mathrm{~km}$ north of the Hawaiian Islands during May and October. These locations are also some distance removed from known summer feeding grounds of the right whale along the Aleutian Peninsula and the Gulf of Alaska (Omura et al., 1968). On the other hand, Gilmore also cited the conclusion of Kenneth Martin of the Kendall Whaling Museum in Massachusetts that no clear evidence existed, historically or recently, that right whales ever wintered in Hawaiian waters. But inspection of the charts by Townsend and Watson (Townsend, 1935), the early Whale Chart prepared by Lieut. M. F. Maury of the U. S. Navy (Maury, 1851), as well as material in Tomilin (1967), clearly shows that in the past it has not been uncommon for right whales to be found in latitudes between $20^{\circ}$ to $25^{\circ}$ throughout the world's oceans. In addition, Tomilin (1967) refers to a report by Reinhardt in 1865 claiming that right whales with large baleen plates occurred in the waters of Hawaii. The Maury Chart also shows a few 'straggling' right whales located as close as $550 \mathrm{~km}$ west of Oahu, as well as other stragglers further to the west, west-southwest and west-northwest, all within 1900 to $2700 \mathrm{~km}$ of the main Hawaiian Islands. Hence, there does appear to be historical evidence for a right-whale presence in Hawaiian waters. The apparent 16-d, or greater, residency of a right whale in Hawaiian waters, as indicated by the current sightings, suggests that this right whale, like the humpbacks, was at a terminal point in its migratory route. Together, the historical and current evidence strengthen the claim that the Hawaiian Islands or other portions of the Hawaiian Archipelago may have been, or still are, a winter assembly area for the right whale.

Though the right whale has been protected by the United States Whaling Treaty Act of 1937, and earlier by the Geneva Conference of 1931, it has apparently not recovered from its severely depleted status. Gilmore (1978) listed its low reproductive rate, competition in its feeding grounds from sei whales, Balenoptera borealis, moving opportunistically into the vacated right whale feeding niche, and possible unreported kills by Russian whalers during the last two decades as potential adverse factors affecting its recovery. Assuming that the Hawaiian-Island region was an important habitat for the right whale, we might speculatively consider an additional reason for the low recovery rate: competition from humpback whales in the Hawaiian assembly area. Herman (1979) suggested that humpback whales may have invaded their current Hawaiian habitat only within the last 200 years. The first documented presence of humpbacks in Hawaiian waters occurred in the mid-nineteenth century, at about the time of intensive whaling for right whales in the Gulf of Alaska (Tomilin, 1967). The reasons for the presumed recent invasion of the Hawaiian habitat by the humpback whale are not clear, but could relate to undesirable ecological changes in old habitats or to an acceleration in dispersion forces due to whaling pressures elsewhere (Herman, 1979). However, there seem to be no cases of different species of baleen whale simultaneously occupying the same breeding area, so that the occupancy of the Hawaiian habitat by the numerically superior humpback whales could have discouraged its use by right whales.

How such displacement might take place is a matter of conjecture. In neither of the two sightings discussed was there evidence that the humpback whales in company with the right whale were acting aggressively towards it, or otherwise discouraging its presence. Possibly, however, the continuous singing of multiple humpback whales day and night in the Hawaiian waters (unpublished field observations) occupies the needed 'acoustic space' for the right whale, which might normally use that space for its own reproductive calls (e. g., Cummings et al., 1972; Payne \& Payne, 1972).

Perhaps the current right-whale presence should be 
classified merely as a 'straggler', as in the early chart of Maury (1851), rather than indicative of a remnant historical breeding population of right whales in the main Hawaiian Islands. But, a straggler from where? Broad expanses of open ocean surround the Hawaiian Islands. As noted earlier, breeding grounds of the North Atlantic and Southern right whales are characteristically close to shore. If there exists an open-ocean winter concentration of right whales from which the sightings in Hawaii derived, it would be atypical of what is known about this species elsewhere. The Northwest Hawaiian Islands, a series of small islets and atolls extending some $1300 \mathrm{~km}$ northwest of the island of Kauai, might be the locale of a winter concentration or right whales contributing stragglers to the main islands. However, we have received no reports of right whales from observers in these areas, although humpback whales are occasionally reported along some of the major atolls. Furthermore, a series of aerial surveys carried out by the University of Hawaii whale research team during the winter of 1977 revealed no right whales. Nonetheless, a more detailed search should be carried out before discounting the Northwest chain as a possible area of concentration.

Optimistically, the sightings in Hawail might be regarded as an indication that right whales are more viable than feared, and are beginning to reoccupy the southern end of their range. This seems to be the case for the eastern North Atlantic stock (Mitchell, 1974). Yet, it may also be that the association with humpbacks is the 'last gasp' of a stock of whales that has difficulty in locating conspecifics. It seems imperative to watch carefully during future winter observations in Hawaii for right whales and to explore, in greater detail, some of the outlying islands of the NorthwestHawaiian chain for a possible remnant population of breeding right whales.

Acknowledgements. We thank Ray Gilmore for his helpful comments on the manuscript and review of our photographs. Dale Rice provided useful information on the historical records of right whales in the North Pacific. Beth Langley of the Lahaina Restoration Foundation and Fred Ball of the Hawaii Civil Air Patrol assisted in the observations of the right whales. The research was supported by the National Science Foundation, Grant BNS77-24943, and is contribution Number 583 from the Hawaii Institute of Marine Biology.

\section{LITERATURE CITED}

Cummings, W. C., Fish, J. F., Thompson, P. O., (1972). Sound production and other behavior of southern right whales (Eubalaena glacialis). Trans. San Diego Soc. nat. Hist. 17: $1-14$

Davies, J. L. (1963). The anti-tropical factor in cetacean speciation. Evolution, Lancaster, Pa. 17: 107-116
Dawbin, W. H. (1966). The seasonal migratory cycle of humpback whales. In: Norris, K. S. (ed.) Whales, dolphins and porpoises, University of California Press, Berkeley, pp. $145-170$

Gilmore, R. M. (1956). Rare right whale visits California. Pacif. Disc. 9: 21-26

Gilmore, R. M. (1969). Populations, distribution and behavior of whales in western South Atlantic: Cruise 69-3 of R/V Hero. Antart. J. U. S. 4: 307-308

Gilmore, R. M. (1978). Right whale. In: Haley, D. (ed.) Marine mammals of eastern North Pacific and arctic waters. Pacific Search Press, Seattle, pp. 62-69

Herman, L. M. (1979). Humpback whales in Hawaiian waters: A study in historical ecology. Pacif. Sci. 33: (in press)

Herman, L. M., Antinoja, R. C. (1977). Humpback whales in the Hawaiian breeding waters: Population and pod characteristics. Sci. Rep. Whales Res. Inst. Tokyo 29: $59-85$

Herman, L. M., Forestell, P. H. (1977). The Hawaiian humpback whale: behaviors. Proc. (Abstracts) 2nd Conf. Biol. Mar. Mammals, San Diego, p. 29

Marr, J. W. (1962). The natural history and geography of Antarctic krill (Euphasia superba). 'Discovery' Rep. 32: 33-464

Maury, M. F. (1851). Whale chart. Series F. National Observatory, Bureau of Ordinance and Hydrographics, Washington, D.C. Nautical chart HO Misc. No. 8514

Mitchell, E. (1974). Present status of northwest Atlantic fin and other whale stocks. In: Schevill, W. E. (ed.) The whale problem: A status report. Harvard University Press, Cambridge, pp. $108-169$

Omura, H., Ohsumi, S., Nemoto, T., Nusu, K., Kasuya, T. (1968). Black right whales in the North Pacific. Sci. Rep. Whales Res. Inst. Tokyo 21: 1-78

Payne, R. S. (1976). At home with right whales. Nat. Geogr. Mag. 149: 322-339

Payne, R. S., Payne, K. (1972). Underwater sounds of southern right whales. Zoologica, N. Y. 56: 159-167

Rice, D. W. (1974). Whales and whale research in the eastern North Pacific. In: Schevill, W. E. (ed.) The whale problem: A status report. Harvard University Press, Cambridge, pp. $170-195$

Rice, D. W., Fiscus, C. H. (1968). Right whales in the southeastern North Pacific. Norsk Hvalfangsttid. 5: 105-107

Rice, D. W., Wolman, A. A. (1971). The life history and ecology of the gray whale (Eschrichtius robustus). American Society of Mammalogists, Stillwater, Oklahoma

Scammon, C. M. (1874). The marine mammals of the northwestern coast of North America, J. H. Carmaney and Co., San Francisco (Republished, Dover Publications Inc., New York 1968)

Tomilin, A. G. (1967). Mammals of the U. S. S. R. and adjacent countries, Vol. IX. Cetacea, Israel Program for Scientific Translations, Jerusalem

Townsend, C. H. (1935). The distribution of certain whales as shown by logbook records of American whaleships Zoologica, N. Y. 19: 3-50

Wada, S (1973). The 9th memorandum on the stock assessment of whales in the North Pacific, Rep. Int. Whal. Comm. 23: 164-169

Wada, S. (1978). Indices of abundance of large-sized whales in the North Pacific in the 1976 whaling season. Rep. Int. Whal. Comm. 28: 319-324

Yablokov, A. V., Bel'kovich, V. M., Borisov, V. I. (1972). Whales and dolphins (Transl. from Russian). Israel Program for Scientific Translations, Jerusalem

This paper was submitted to the editor; it was accepted for printing on January 10,1980 